\title{
Racikan Strategi Pemberian Kredit di Bank Perkreditan Rakyat
}

\author{
Anak Agung Gede Adnya Prasta ${ }^{(1)}$ \\ Luh Putu Mahyuni ${ }^{(2)}$
}

\author{
BPR Balaguna Perasta ${ }^{(1)}$ \\ Universitas Pendidikan Nasional ${ }^{(2)}$ \\ aaprasta96@gmail.com ${ }^{(1)}$ \\ lpmahyuni@gmail.com ${ }^{(2)}$
}

\begin{abstract}
Along with the decline in interest rates given while the interest rates of third party funds did not experience a decline from the previous year. This indicates that there is an inverse comparison between the savings interest rate and the loan interest rate, where the comparison should be directly proportional to the interest rate of the savings and the interest rate on the loan. This research was conducted at PT. BPR. Balaguna Perasta, whose address is batutabih no. 99x Klungkung District, Klungkung Regency, Bali Province. The reason for conducting research is because of the level of competition in tight lending rates in line with the reduction in LPS (Deposit Insurance Corporation) interest rates, besides that this research was conducted because of the loan interest rates given by PT. BPR Balaguna Perasta is smaller than the average market interest rate. Data type consists of quantitative data and qualitative data collected from primary and secondary data, through data collection techniques, documentation and interview studies to 3 informants, and data validity testing techniques using triangulation with sources and using quantitative and qualitative analysis techniques. With the calculation of the average interest rate on BPR loans in Klungkung Regency at 21.6\% pa, the channeling of loans provides an average loan interest rate of $19.1 \% \mathrm{pa}$ (according to the 2018 financial report), and based on the calculation of the base landing rate above is obtained at $20.77 \%$, so the interest rate determination made by the Rural Credit Bank (BPR) Balaguna Perasta in Klungkung Regency is not yet ideal. In giving and lending to banks, it is always based on the rules / procedures for granting credit by applying the precautionary principle. Especially, it has applied the $5^{\prime} \mathrm{C}$ principle which includes analysis of character, capacity, capital, collateral, condition of economic in addition to the procedure of lending in accordance with Bank Indonesia regulations, namely credit application requirements, credit granting limits, loan interest rates, and all sanctions in accordance with regulations specified. So that the Interest Rate Determination Strategy for increasing credit sales in the Balaguna Perasta Rural Credit Bank (BPR) in Klungkung Regency does not affect much in the provision of security/ineffectiveness.
\end{abstract}

Keywords: Bank Funding Costs; Banking Credit; Smal Medium Banking; Banking Strategy 
Seiring dengan penurunan tingkat suku bunga yang diberikan sedangkan suku bunga dana pihak ketiga tidak mengalami penurunan dari tahun sebelumnya. Hal ini menandakan adanya perbandingan terbalik antara suku bunga tabungan dengan suku bunga kredit dimana seharusnya perbandingan tersebut berbanding lurus antara suku bunga tabungan dan suku bunga kredit. Penelitian ini dilaksanakan di PT. BPR. Balaguna Perasta yang beralamat jalan batutabih no. 99x Kecamatan Klungkung, Kabupaten Klungkung, Propinsi Bali. Adapun alasan mengadakan penelitian adalah karena adanya tingkat persaingan suku bunga kredit yang ketat seiring dengan penurunan suku bunga LPS (Lembaga Penjamin Simpanan) selain itu penelitian ini dilakukan karena suku bunga kredit yang diberikan PT. BPR Balaguna Perasta lebih kecil dari rata-rata suku bunga pasar. Jenis Data terdiri dari Data kuantitatif dan Data kwalitatif yang dikumpulkan dari Data Primer dan Data Sekunder, melalui Teknik Pengumpulan Data Studi Dokumentasi dan Wawancara kepada 3 orang informan, serta teknik pengujian keabsahan data menggunakan Triangulasi dengan sumber dan menggunakan teknik analisis Kuantitatif dan kualitatif. Dengan hasil perhitungan rata-rata tingkat suku bunga kredit BPR di Kabupaten Klungkung sebesar $21.6 \%$ p.a, Sedamgkan penyaluran krditnya memberikan suku bunga kredit rata-rata sebesar 19,1 \% p.a (sesuai laporan keuangan 2018), dan berdasarkan hasil perhitungan base landing rate tersebut di atas di diperoleh sebesar 20,77\%, sehingga dengan demikian penetapan suku bunga yang dilakukan oleh Bank Perkreditan Rakyat (BPR) Balaguna Perasta di Kabupaten Klungkung belum ideal. Dalam memberi dan pinjaman kredit bank selalu berpatokan kepada aturan/prosedur pemberian kredit dengan menerapkan prinsip kehati-hatian. Terutama telah menerapkan prinsip 5'C yang mencakup analisa character, capacity, capital, collateral, condition of economic disamping prosedur pemberian kredit sesuai dengan ketentuan Bank Indonesia yakni syarat pengajuan kredit, batas kewenangan pemberian kredit, suku bunga kredit, sanksi yang diberikan semuanya sesuai dengan peraturan yang ditetapkan. Sehingga dengan demimkian Strategi Penetapan Suku Bunga untuk meningkatkan penjualan kredit di Bank Perkreditan Rakyat (BPR) Balaguna Perasta di Kabupaten Klungkung tidak banyak mempengaruhi dalam pemberian kedit tidak efektif.

Kata Kunci : Biaya Dana Bank; Kredit Bank; Bank Perkreditan Rakyat; Strategi Bank 


\section{PENDAHULUAN}

Usaha perbankan meliputi tiga kegiatan utama yaitu menghimpun dana, menyalurkan dana dan memberikan jasa bank lainnya sedangkan penyaluran dana terhadap masyarakat salah satunya dapat dilakukan melalui pemberian kredit (Permanasari dan Darma, 2013). Ditambahkan Dewi dan Darma (2016) menyatakan bahwa : Kredit adalah penyediaan uang tagihan yang dapat dipersamakan dengan itu, berdasarkan persetujuan atau kesepakatan pinjam-meminjam antara bank dengan pihak lain, yang mewajibkan pihak peminjam untuk melunasi utangnya setelah jangka waktu tertentu dengan jumlah bunga, imbalan atau pembagian hasil keuntungan, termasuk pembelian surat berharga nasabah yang dilengkapi dengan NPA (note purchase agreement) dan pengambilalihan tagihan dalam rangka kegiatan anjak piutang (Samadiartha dan Darma, 2017).

Bunga kredit merupakan pendapatan atas penanaman dana (Arsriani dan Darma, 2013). Namun semakin ketatnya persaingan pada lembaga keuangan yaitu bank untuk mencari sumber dana dari masyarakat sehingga akan berpengaruh terhadap suku bunga serta biaya dan cukup tinggi, persaingan tidak begitu bagus antar lembaga keuangan maka Bank Indonesia (BI) sebagai Badan Pengawas Monoter dan tugas BI sesuai dengan UU.Bo; 23 tahun 1999 tentang Bank Indonesia sebagaimana telah diubah dengan UU No. 3 tahun 2004 tujuan Bank Indonesia adalah mencapai dan memelihara kestabilan nilai rupiah (pasal 7) dan kebijakan monoter yang dikeluarkan oleh BI sebagai acuan dari lembaga keuangan atau Bank dalam pelaksanaan opearasional yaitu perubahan kenaikan atau penurunan BI Rate (Budiasni dan Darma, 2016).

PT. BPR. Balaguna Perasta Klungkung yang merupakan salah satu lembaga keuangan dimana kegiatan sehari harinya memberikan kredit kepada masyarakat dan menghimpun dana dari masyarakat dalam bentuk deposito berjangka, dan tabungan. Dalam hal penerimaan dana masyarakat PT. BPR. Balaguna Perasta Klungkung memberikan jasa bunga. Selanjutnya jasa bunga yang dikeluarkan oleh bank adalah biaya bunga simpanan untuk deposito berjangka dan tabungan. Berikut pencapaian tabungan, deposito dan kredit PT. BPR. Balaguna Perasta Klungkung pada tahun 2016-2018 adalah sebagai berikut : 


\section{Tabel 1.1}

Tabungan, Deposito dan Kredit

Di PT. BPR. Balaguna Perasta Klungkung

\begin{tabular}{|l|r|c|c|c|c|c|}
\hline \multicolumn{2}{|c|}{ Tahun 2016-2018 } & Kredit & $\begin{array}{c}\text { Suku } \\
\text { Bunga }\end{array}$ \\
\hline 2016 & 5.448 .991 .000 & $4 \%$ p.a & 10.261 .850 .000 & $11 \%$ p.a & 14.765 .683 .000 & $22,8 \%$ p.a \\
\hline 2017 & 4.909 .953 .000 & $4 \%$ p.a & 10.686 .900 .000 & $10 \%$ p.a & 15.205 .691 .000 & $21,6 \%$ p.a \\
\hline 2018 & 5.082 .347 .000 & $4 \%$ p.a & 12.652 .500 .000 & $10 \%$ p.a & 16.216 .758 .175 & $19.1 \%$ p.a \\
\hline
\end{tabular}

Sumber : PT. BPR. Balaguna Perasta Klungkung

Berdasarkan tabel 1 tersebut, dapat dilihat bahwa dari tahun 2016 ke tahun 2017 terjadi peningkatan pencapaian produk deposito dan kredit sedangkan produk tabungan mengalami penurunan. Begitu pula ditahun 2017 ke tahun 2018 semua produk mengalami peningkatan, hal ini mencerminkan bahwa BPR Perasta dipercaya oleh masyarakat dan tumbuh dengan baik.

Dari data tahun 2017 ke tahun 2018 tersebut terlihat bahwa kredit mengalami peningkatan secara signifikan yang disebabkan karena PT. BPR. Balaguna Perasta Klungkung menurunkan suku bunga kredit. Seiring dengan penurunan tingkat suku bunga yang diberikan sedangkan suku bunga dana pihak ketiga tidak mengalami penurunan dari tahun sebelumnya. Hal ini menandakan adanya perbandingan terbalik antara suku bunga tabungan dengan suku bunga kredit dimana seharusnya perbandingan tersebut berbanding lurus antara suku bunga tabungan dan suku bunga kredit. Namun dalam kenyataan bank dalam menentukan tingkat suku bunga kredit mempergunakan harga pasar dengan membandingkan beberapa Bank Perkreditan Rakyat (BPR) yang ada di Kabupaten Klungkung. Adapun Bank Perkreditan Rakyat (BPR) tersebut adalah : 
Tabel 1.2

Rata- Rata Tingkat Suku Bunga Pertahun

Pada Bank Perkreditan Rakyat di Klungkung

Tahun 2019

\begin{tabular}{|l|l|l|c|}
\hline No. & Nama Bank & Alamat & $\begin{array}{c}\text { Tingkat Suku } \\
\text { Bunga }\end{array}$ \\
\hline 1 & PT. BPR. Tridarma Putri & Jl. Diponegoro No.25 Klungkung & 22,8 \\
\hline 2 & PT. BPR. Artha Rengganis & Jl. Raya Batutabih Klungkung & 20.4 \\
\hline 3 & PT. BPR. Sinar Putramas & Jl. Raya Kecubung Klungkung & 22,8 \\
\hline 4 & PT. BPR. Sari Jaya Sedana & Jl. Raya Sampalan Klungkung & 20,4 \\
\hline 5 & PT. BPR. Tata Anjung Sari & Didalam Pasar Klungkung & 24 \\
\hline 6 & PT. BPR.Nusamba Mangis & Jl. Untung Surapati Klungkung & 19,2 \\
\hline 7 & $\begin{array}{l}\text { PT. BPR.Dewata candra } \\
\text { Dana }\end{array}$ & $\begin{array}{r}\text { Jl. Nakula Klungkung } \\
\text { Bumlah Suku Bunga } \\
\text { Periode }\end{array}$ & $\mathbf{1 5 1 , 2}$ \\
\hline
\end{tabular}

Dari data tersebut nampak bahwa PT. BPR. Balaguna Perasta Klungkung memberikan suku bunga di bawah rata-rata suku bunga pasar, sehingga dengan strategi penurunan tingkat suku bunga di harapkan dapat meningkatkan kinerja perkreditan bank serta pertumbuhan UMKM di Kabupaten Klungkung. Berdasarkan uraian diatas, maka peneliti tertarik untuk mengkaji tentang Racikan Strategi Pemberian Kredit di Bank Perkreditan Rakyat (BPR)

\section{Kebijakan Pemberian Kredit}

Didalam menentukan standar kredit, biasanya perusahaan akan mempertimbangkan beberapa faktor yang berhubungan dengan siapa dan dalam jumlah berapa kredit yang akan diberikan (Patni dan Darma, 2017). (Lukman Syamsudin: 2001) menyatakan bahwa faktorfaktor utama yang harus dipertimbangkan apabila perusahaan ingin merubah standar kredit yang diterapkan adalah sebagai berikut :
1) Biaya-biaya administrasi
2) Investasi dalam piutang 
3) Kerugian piutang

4) Volume penjualan

Analisa Kredit

Dalam mengadakan penilaian terhadap calon langganan yang akan diberikan kredit perlu diperhatikan dua faktor yaitu :

1) Informasi tentang keadaan langganan,

2) Menganalisa laporan keuangan

3) Persyaratan Kredit

Keuntungan-keuntungan Pemberian Kredit

Didalam politik penjualan kredit akan menimbulkan adanya piutang, dengan mempertahankan piutang akan dapat menimbulkan keuntungan dalam bentuk :

1) Kenaikan hasil penjualan

2) Kenaikan laba

3) Memenangkan persaingan

Prinsip-Prinsip Kredit

Sudirman (1999) menyatakan bahwa prinsip 5C perkreditan tersebut adalah :

1. Character

2. Capacity

3. Capital

4. Collateral

5. Condition of Economic

Jenis-jenis Kredit

1) Dilihat dari segi kegunaan.

(a) Kredit investasi

(b) Kredit modal kerja.

2) Dilihat dari segi tujuan kredit.

1. Kredit produktif.

2. Kredit konsumtif.

3. Kredit perdagangan. 
3) Dilihat dari segi jangka waktu.
a. Kredit jangka pendek.
b. Kredit jangka menegah
c. Kredit jangka Panjang

4) Dilihat dari segi jaminan.
a. Kredit dengan jaminan.
b. Kredit Tanpa Jaminan.

5) Dilihat dari segi sektor usaha.
a. Kredit pertanian,
b. Kredit perternakan,
c. Kredit industri,
d. Kredit pertambangan,
e. Kredit pendidikan,
f. Kredit profesi,
g. Kredit perumahan,
h. Dan sektor-sektor lainnya.

\section{Biaya}

Menurut (Mulyadi: 2001, dipertegas kembali oleh Adnyasuari dan Darma (2017) menyatakan bahwa: "Biaya dalam arti luas adalah pengorbanan sumber ekonomi, yang diukur dalam satuan uang yang telah terjadi atau yang kemungkinan akan terjadi untuk tujuan tertentu".

Jadi ada 4 (empat) unsur pokok dalam definisi tersebut di atas :

1) Biaya merupakan pengorbanan sumber ekonomi

2) Diukur dalam satuan uang

3) Yang telah terjadi atau yang secara potensial akan terjadi

4) Pengorbanan tersebut untuk tujuan tertentu

Menurut Hartanto (2003) menyatakan bahwa perbedaan antara pengertian cost (biaya) dengan expsense (ongkos) sebagai berikut cost adalah biaya-biaya yang dianggap akan memberikan manfaat (service potensial) di waktu yang akan datang dan karenanya merupakan aktivitas yang dicantumkan dalam neraca. Sebaliknya expense dan expired cost adalah biayabiaya yang telah digunakan untuk menghasilkan prestasi." Karenanya jenis-jenis biaya ini dapat memberikan manfaat lagi di waktu yang akan datang, maka tempatnya adalah diperkirakan laba rugi dan bukan neraca. 
Berdasarkan pendapatan di atas, maka dapat disimpulkan bahwa biaya adalah jumlah yang dinyatakan dengan uang, digunakan untuk mendapatkan sesuatu yang bermanfaat bukan saja pada tahun yang terjadinya pengorbanan, tetapi juga memberikan manfaat pada tahuntahun mendatang.

\section{Biaya Dana Bank}

Menurut Siamat (2005) menyatakan bahwa : "Biaya dana pada dasarnya adalah biaya bunga yang dinyatakan oleh bank atas keseluruhan dana yang dihimpun dari berbagai sumber". Jadi Biaya Dana adalah cost of funds yaitu biaya yang harus dibayar oleh suatu lembaga keuangan atau bank atas penggunaan uang yang sumbernya dari pihak lain (nasabah dan/atau bank); biaya dana dalam suatu bank merupakan dasar penetapan suku bunga kredit setelah memperhitungkan keuntungan atau laba yang diharapkan termasuk biaya administrasi dan biaya-biaya lain (Rusmadewi dan Darma, 2018).

\section{Sumber-sumber Dana Bank}

Menurut Siamat: (2005) menyatakan bahwa sumber utama dana bank berasal simpanan dalam bentuk giro (demand deposit), deposito berjangka (time deposit) dan tabungan (saving deposit). Ketiga jenis dana ini sering disebut sebagai sumber dana tradisional bank. Sumbersumber dana bank dalam bentuk simpanan tersebut dapat berasal dari masyarakat maupun dari nasabah institusi. Disamping itu, sumber dana bank dapat pula berasal dari modal dan sumber lainnya yang tidak termasuk dari kedua sumber tersebut di atas.

\section{Jenis-Jenis Biaya Overhead Dana Bank}

Siamat (2005) menyatakan bahwa komponen biaya yang diperhitungkan dalam biaya overhead ini adalah semua biaya yang dikeluarkan bank dalam kegiatan penghimpunan dana dari berbagai sumber yang menjadi beban rugi laba, antara lain adalah : beban personalia, administrasi umum dan beban lainnya.(Kasmir : 2004) menyatakan bahwa dalam melakukan setiap kegiatan setiap bank membutuhkan berbagai sarana dan prasarana baik berupa manusia maupun alat. Penggunaan sarana dan prasarana ini memerlukan sejumlah biaya yang harus ditanggung bank sebagai biaya operasi. Biaya operasi merupakan biaya yang dikeluarkan oleh bank dalam melaksanakan operasinya. Biaya ini terdiri dari biaya gaji pegawai, biaya administrasi, biaya pemeliharaan dan biaya-biaya lainnya.

\section{Cost of Loonable Funds}

Menurut Siamat (2005) menyatakan bahwa Cost of loonable funds adalah biaya dana yang dikeluarkan bank setelah memperhitungkan ketentuan cadangan likuiditas wajib (reserve 
requirement). Ketentuan requirement ini dinyatakan dalam persentase tertentu dari jumlah dana yang diterima dari masyarakat (dana pihak ketiga). Jumlah inilah selanjutnya disebut cadangan likuiditas wajib yang harus selalu tersedia di sisi aset neraca bank baik dicatat dalam pos kas atau giro pada bank sentral.

\section{Bunga}

Kasmir (2004) menyatakan bahwa bunga bank daat diartikan sebagai balas jasa yang diberikan oleh bank yang berdasarkan prinsip konvesional kepada nasabah yang membeli atau menjual produknya. Bunga dapat diartikan sebagai harga yang harus dibayarkan kepada nasabah (yang memiliki simpnan) dengan yang harus dibayar oleh nasabah kepada bank (nasabah yang memperoleh pinjaman). Lebih lanjut (Kasmir : 2004) menyatakan bahwa dalam kegiatan perbankan sehari-hari ada 2 macam bunga yang diberikan kepada nasabah yaitu : Bunga Simpanan dan Bunga Pinjaman. Kedua macam bunga ini merupakan komponen utama faktor biaya dan pendapatan bagi bank. Bunga simpanan merupakan biaya dan yang harus dikeluarkan kepada nasabah, sedangkan bunga pinjaman merupakan pendapatan yang diterima dari nasabah (Dewi dan Darma, 2019).

a. Faktor-faktor Yang Mempengaruhi Penentuan Suku Bunga Kredit.

Menurut Kasmir (2004) menyatakan bahwa faktor-Faktor utama yang mempengaruhi besar kecilnya penetapan suku bunga adalah sebagai berikut :

(a) Kebutuhan dana

(b) Persaingan.

(c) Kebijaksanan pemerintah.

(d) Target laba yang di inginkan.

(e) Jangka waktu.

(f) Kualitas jaminan.

(g) Reputasi perusahan.

(h) Produk yang kompetitif.

(i) Hubungan baik.

(j) Jaminan pihak ketiga.

Lebih lanjut (Kasmir: 2004) menyatakan bahwa khusus untuk menentukan besar kecilnya suku bunga kredit yang akan diberikan kepada para debitur terdapat beberapa komponen yang mempengaruhi. Komponen-komponen ini ada yang dapat diperkecil 
(dikurangi) dan ada juga yang tidak. Adapun komponen dalam mementukan suku bunga kredit antara lain :
(a) Total Biaya Dana (Cost of Fund).
(b) Biaya operasi (Overhead)
(c) Cadangan resiko kredit macet (Premi Resiko).
(d) Laba yang diinginkan (Spread).
(e) Pajak.

\section{Penilaian Resiko Kredit}

(Kasmir: 2004) menyatakan bahwa sepandai apapun analisis kredit dalam menganalisia setiap permohonan kredit, kemungkinan kredit tersebut macet pasti ada, hal ini disebabkan oleh 2 unsur sebagai berikut :

a. Dari pihak perbankan.

Artinya dalam melakukan analisisnya pihak analisis kurang teliti, sehingga apa yang seharusnya terjadi, tidak diprediksi sebelumnya. Dapat pula terjadi akibat kolusi dari pihak analisis kredit dengan pihak debitur sehingga dalam analisisnya dilakukan secara subjektif

b. Dari pihak nasabah.

Dari pihak nasabah kemacetan kredit dapat dilakukan akibat 2 hal yaitu:

1) Adanya unsur kesengajaan. Dalam hal ini nasabah sengaja untuk tidak bermaksud membayar kewajibannya kepada bank sehingga kredit yang diberikan macet. Dapat dikatakan tidak adanya unsur kemauan untuk membayar.

2) Adanya unsur tidak sengaja. Artinya debitur mau membayar akan tetapi tidak mampu. Sebagai contoh kredit yang dibiayai mengalami musibah seperti kebakaran, kena hama, kebanjiran dan sebagainya. Sehingga kemampuan untuk membayar tidak ada.

Dalam hal kredit macet pihak bank perlu melakukan penyelamatan, sehngga tidak akan menimbulkan kerugian. Penyelamatan yang dilakukan apakah denga memberikan kringanan berupa jangka waktu atau angsuran terutama bagi kredit terkena musibah atau melakukan penyitaan bagi kredit yang sengaja lalai untuk membayar. Terhadap kredit yang mengalami kemacetan sebaiknya dilakukanpenyelamatan sehingga bank tidak mengalami kerugian. Penyelamatan terhadap kredit macet dilakukan dengan cara antara lain: 


\section{Rescheduling}

a. Memperpanjang jangka waktui kredit. Dalam hal inidebitur diberikan keringanan dalam masalah jangka waktu kredit misalnya perpanjangan jangka waktu kredit dari 6 bulan menjadi 1 tahun sehingga debitur mempunyai waktu yang lebih lama untuk mengembalikannya.

b. Memperpanjang jangka waktu angsuran. Memperpanjang angsuran hampir sama dengan jangka waktu kredit. Dalam hal ini jangka waktu angsuran kreditnya diperpanjang pembayarannya pun misalnya dari 36 kali menjadi 48 kali dan hal ini tentu saja jumlah angsuran pun menjadi mengecil seiring penambahan jumlah angsuran.

\section{Reconditioning.}

Dengan cara mengubah berbagai persyaratan yang ada seperti :

a. Kapitalisasi bunga, yaitu bunga dijadikan hutang pokok.

b. Penundaan pembayaran bunga sampai waktu tertentu. Dalam hal penundaan pembayaran bunga sampai waktu tertentu, maksudnya hanya bunga yang dapat ditunda pembayarannya, sedangkan pokok pinjamannya tetap harus dibayar seperti biasa.

c. Penurunan suku bunga penurunan suku bunga dimaksudkan agar lebih meringankan beban nasabah. Sebagai contoh jika bunga pertahun sebelumnya dibebankan $20 \%$ diturunkan menjadi 18\%. Hal ini tergantung dari pertimbangan yang bersangkutan. Penurunan suku bunga akan mempengaruhi jumlah angsuran yang semakin mengecil, sehingga diharapkan dapat membantu meringankan nasabah.

d. Pembebasan bunga. Dalam hal pembebasan suku bunga diberikan kepada nasabah dengan pertimbangan nasabah sudah akan mampu lagi membayar kredit tersebut. Akan tetapi nasabah tetap mempunyai kewajiban untuk membayar pokok pinjamannya sampai lunas.

3. Restructuring.

a. Dengan menambah jumlah kredit.

b. Dengan menambah equity: dengan menyetor uang tunai dan tambahan dari pemilik.

4. Kombinasi. Merupakan kombinasi dari ketiga jenis diatas.

5. Penyitaan jaminan. Penyitaan jaminan merupakan jalan terakhir apabila nasabah sudah benar-benar tidak punay etikad baik ataupaun sudah taidak mampu lagi untuk membayar semua hutang-hutangnya. 


\section{Kerangka Pemikiran}

Dana pihak ketiga merupakan komposisi dana yang paling besar dan berpengaruh terhadap kegiatan operasional bank. Penghimpun dana dari masyarakat dapat dikatakan relative lebih mudah jika dibandingkan dengan dana lainnya, keuntungan dari dana yang berasal dari masyarakat adalah jumlahnya tidak terbatas. Sebagian besar modal yang dimiliki oleh bank adalah bersumber dari dana masyarakat ini (dana pihak ketiga).

Sebagai salah satu fungsinya bank melakukan kegiatan penghimpunan dana dari masyarakat atau pihak yang kelebihan dana (surplus unit). Pembiayaan merupakan aktivitas lainnya yang sangat penting karena dengan adanya pembiayaan akan diperoleh sumber pendapatan utama dan menjadi penunjang kelangsungan usaha suatu bank. Pembiayaan atau penyaluran pembiayaan adalah salah satu fungsi bank lainnya, yaitu menyalurkan dana dari pihak yang kelebihan dana (surplus unit) pihak yang kekurangan dana (defisit unit) dengan berbagai produk pembiayaan yang ditetapkan pada bank.

Salah satu sarana penting bagi bank dalam pemberian pembiayaan adalah menghasilkan laba atau keuntungan. Oleh karena itu jumlah laba yang dihasilkan perusahaan dapat digunakan sebagai alat ukur efektif karena laba adalah selisih antara pendapatan dan biaya dari satu kesatuan perusahaan untuk jangka waktu tertentu.

Dari uraian di atas, maka dapat digambarkan bahwa kerangka pikir terhadap dengan Racikan Strategi Pemberian Kredit di Bank Perkreditan Rakyat (BPR) Balaguna Perasta di Kabupaten Klungkung adalah sebagai berikut :

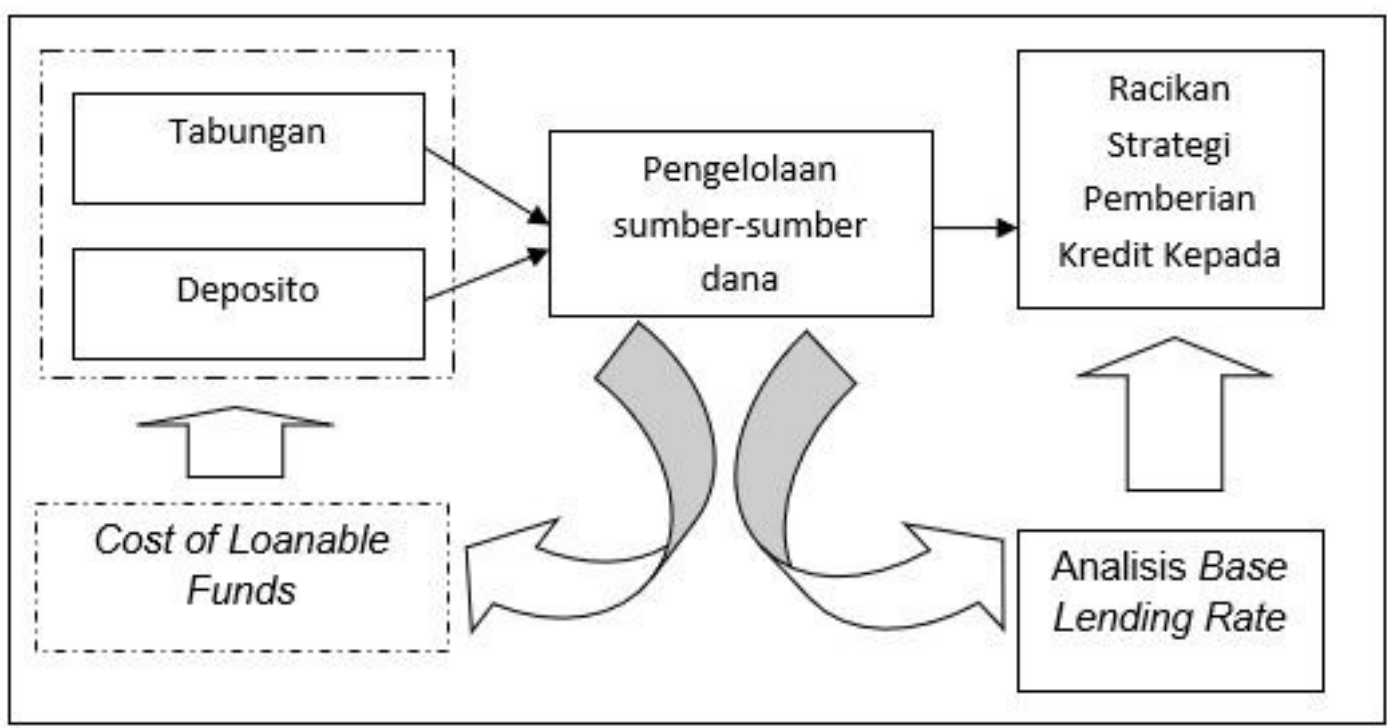

Sumber : Hasil Penelitian (diolah) 


\section{METODE PENELITIAN}

Penelitian ini dilaksanakan di PT. BPR. Balaguna Perasta yang beralamat jalan batutabih no. 99x Kecamatan Klungkung, Kabupaten Klungkung, Propinsi Bali. Adapun alasan mengadakan penelitian adalah karena adanya tingkat persaingan suku bunga kredit yang ketat seiring dengan penurunan suku bunga LPS (Lembaga Penjamin Simpanan) selain itu penelitian ini dilakukan karena suku bunga kredit yang diberikan PT. BPR Balaguna Perasta lebih kecil dari rata-rata suku bunga pasar. Jenis Data terdiri dari Data kuantitatif dan Data kwalitatif yang dikumpulkan dari Data Primer dan Data Sekunder, melalui Teknik Pengumpulan Data Studi Dokumentasi dan Wawancara kepada 3 orang informan, serta teknik pengujian keabsahan data menggunakan Triangulasi dengan sumber dan menggunakan teknik analisis Kuantitatif dan kualitatif.

\section{Hasil Penelitian}

\section{a. Analisis Penetapan suku bunga kredit di Bank Perkreditan Rakyat}

Untuk mencapai tujuan PT. BPR. Balaguna Perasta Klungkung seperti yang telah direncanakan, maka perusahaan harus melakukan kegiatan atau usaha. Dalam usaha untuk mencapai tujuan perusahaan ada beberapa kegiatan yang harus dilakukan antara lain

\section{Memberikan Kredit}

Sesuai dengan bidang usaha bank perkreditan rakyat salah satunya adalah untuk memberikan kredit, PT. BPR. Balaguna Perasta Klungkung juga telah mengeluarkan kredit untuk masyarakat Kabupaten Klungkung dan sekitarnya. Kredit atau pinjaman yang diberikan oleh PT. BPR. Balaguna Perasta Klungkung dengan suku bunga yang diberikan dapat dilihat pada tabel berikut ini.

Tabel 4.1

Jangka Waktu Kredit, Jumlah Debitur dan Nilai Nominal PT. BPR. Balaguna Perasta Klungkung

Tahun 2018

\begin{tabular}{|c|c|c|c|}
\hline No. & $\begin{array}{l}\text { Jangka Waktu } \\
\text { (Tahun) }\end{array}$ & $\begin{array}{l}\text { Jumlah } \\
\text { Debitur } \\
\text { (Orang) }\end{array}$ & $\begin{array}{l}\text { Nominal } \\
\text { (Rp) }\end{array}$ \\
\hline 1 & 1 & 280 & 1.985 .632 .900 \\
\hline 2 & 2 & 1.085 & 12.189 .741 .275 \\
\hline 3 & 3 & 40 & 2.041 .384 .000 \\
\hline & Jumlah & 1405 & 16.216 .758 .175 \\
\hline
\end{tabular}

Sumber : PT. BPR. Balaguna Perasta Klungkung 
Berdasarkan tabel 4.1 di atas, maka dapat dijelaskan bahwa :

a. Jumlah debitur di PT. BPR. Balaguna Perasta Klungkung untuk jangka waktu satu tahun adalah 280 orang dengan nominal Rp. 1.985.632.900

b. Jumlah debitur di PT. BPR. Balaguna Perasta Klungkung untuk jangka waktu dua tahun adalah 1.085 orang dengan nominal Rp. 12.189.741.275.

c. Jumlah debitur di PT. BPR. Balaguna Perasta Klungkung untuk jangka waktu tiga tahun adalah 1085 orang dengan nominal Rp. 2.041.384.000.

Berdasarkan data diatas bahwa terlihat pada jangka waktu 2 tahun penyaluran kredit lebih banyak dibandingkan jangka 1 tahun dan 3 tahun, hal ini disebabkan oleh banyaknya kredit UMKM yang disalurkan oleh PT, BPR Balaguna Perasta yang mana diketahui bahwa kredit UMKM memiliki jangka waktu kredit maksimum 2 tahun.

2. Menerima Simpanan.

Untuk dapat memberikan kredit kepada masyarakat, bank memerlukan sumber dana yang kuat. Dalam menyalurkan kredit PT. BPR. Balaguna Perasta Klungkung tidak hanya mengandalkan sumber dana dari pemiliknya saja, tetapi jga dari penerima simpanan dari nasabah. Adapun bentuk simpanan yang diperoleh dari nasabah sebagai berikut:

\section{a. Deposito}

Deposito merupakan simpanan nasabah pada bank yang pengambilannya boleh dilakukan apabila simpanan tersebut sudah jatuh tempo atau sering disebut dengan simpanan berjangka. Deposito dipilih oleh nasabah yang mempunyai dana segar dengan mengharapkan pendapatanatas bunga, karena suku bunga deposito lebih besar dari suku bunga tabungan. Adapun rincian suku bunga deposito yang berlaku sesuai dengan jangka waktu dan nominal deposito pada PT. BPR. Balaguna Perasta Klungkung sesuai dengan tabel 4.2 berikut : 
Tabel 4.2

Suku Bunga Deposito

PT. BPR. Balaguna Perasta Klungkung

\begin{tabular}{|r|c|c|r|}
\hline Jangka Waktu & $\begin{array}{c}\text { Bunga Setahun } \\
(\%)\end{array}$ & $\begin{array}{c}\text { Bunga Sebulan } \\
(\%)\end{array}$ & Jumlah Dana \\
\hline 12 Bulan & 10 & 0,83 & 1.106 .050 .000 \\
\hline 6 Bulan & 8 & 0,67 & 4.642 .050 .000 \\
\hline 3 Bulan & 6 & 0,5 & 4.112 .000 .000 \\
\hline 1 Bulan & 5 & 0,42 & 2.792 .400 .000 \\
\hline
\end{tabular}

Sumber : PT. BPR. Balaguna Perasta Klungkung

Dari tabel diatas terlihat bahwa semakin panjang jangka waktu deposito maka semakin besar bunga yang diberikan oleh PT. BPR Balaguna Perasta, dengan suku bunga tertinggi sebesar $10 \%$ p.a (sesuai suku bunga LPS).

b. Tabungan

Selain simpanan berjangka (deposito) PT. BPR. Balaguna Perasta Klungkung juga menerima simpanan dalam bentuk tabungan. Dalam menghimpun dana dalam bentuk tabungan bank memberikan fasilitas lebih kepada nasabahnya dengan menggunakan sistem kolektor yang mana tabungan dikolek setiap harinya tanpa nasabah harus datang kekantor. Tingkat suku tabungan yang diberikan sebesar 4\% p.a yang dihitung dari saldo minimum nasabah. Adapun jumlah tabungan dapat pada tahun 2018 adalah sebesar Rp 5.082.347.000.

3. Rata-Rata Tingkat Suku Bunga Kredit Bank Perkreditan Rakyat di Klungkung Selain PT. BPR. Balaguna Perasta terdapat 7 Bank Perkreditan Rakyat Klungkung, dimana suku bunga yang dipasarkan masing-masing bank tersebut pada tahun 2018 berbeda-beda antara lain: 
Tabel 4.3

Rata- Rata Tingkat Suku Bunga

Pada Bank Perkreditan Rakyat di Klungkung

\begin{tabular}{|l|l|l|c|}
\hline No. & Nama Bank & Alamat & Tingkat Suku Bunga \\
& & & Pertahun \\
\hline 1 & PT. BPR. Tridarma Putri & Jl. Diponegoro No.25 Klungkung & 22,8 \\
\hline 2 & PT. BPR. Artha Rengganis & Jl. Raya Batutabih Klungkung & 20.4 \\
\hline 3 & PT. BPR. Sinar Putramas & Jl. Raya Kecubung Klungkung & 22,8 \\
\hline 4 & PT. BPR. Sari Jaya Sedana & Jl. Raya Sampalan Klungkung & 20,4 \\
\hline 5 & PT. BPR.Tata Anjung Sari & Didalam Pasar Klungkung & 24 \\
\hline 6 & PT. BPR.Nusamba Mangis & Jl. Untung Surapati Klungkung & 19,2 \\
\hline 7 & PT. BPR.Dewata candra Dana & Jl. Nakula Klungkung & 21,6 \\
\hline Jumlah Suku Bunga & & $\mathbf{1 5 1 , 2}$ \\
\hline \multicolumn{2}{|l|}{ Rata-rata Suku Bunga Per Periode } & $\mathbf{2 1 , 6}$ \\
\hline
\end{tabular}

Sumber : Hasil penelitian

Berdasarkan tabel diatas terlihat bahwa rata-rata tingkat suku bunga kredit yang dipasarkan oleh BPR di Klungkung sebesar 21.6\% p.a, sedangkan PT. BPR. Balaguna Perasta mampu memberikan menyalurkan suku bunga kredit rata-rata sebesar 19,1 \% p.a (sesuai laporan keuangan 2018).

\section{Perhitungan Biaya Dana (Cost of Fund)}

Sebelum menganalisis perhitungan cost of loanable fund terlebih dahulu kita mencari rata-rata tertimbang dari biaya dana tabungan dan biaya dana deposito berjangka. Biaya dana pada dasarnya adalah biaya bunga yang dibayarkan oleh bank atas keseluruhan dana yang dihimpun dari berbagai sumber. Untuk menghitung biaya dana yang bersumber dari tabungan dan deposito berjangka terlebih dahulu harus mencari biaya dana rata-rata tertimbang dari masing-masingdana tersebut, karena sumber-sumber dana ini memiliki tingkat bunga yang ditentukan berdasarkan jumlah saldo dan jangka waktu. Bank memberikan jasa deposito berjangka berdasarkan tingkat bunga yang di pengaruhi oleh jangka waktu jatuh temponya, demikian juga sumber dana dari tabungan, dimana tingkat bunganya di hitung dari jumlah saldo tabungan dan lamanya mengendap di bank. 
Dengan adanya karekteristik tersebut, maka untuk mengetahui biaya dana, sumber dana bank tersebut harus dihitung berdasarkan rata-rata tertimbang dan disajikan dalam tabel 4.4 dibawah ini :

Tabel 4.4

Biaya Dana Tabungan

PT. BPR. Balaguna Perasta Klungkung

Tahun 2018

\begin{tabular}{|l|c|c|c|}
\hline Tahun & $\begin{array}{c}\text { Jumlah Tabungan } \\
\text { (Rp) }\end{array}$ & $\begin{array}{c}\text { Tingkat Bunga } \\
\text { (\%) }\end{array}$ & $\begin{array}{c}\text { Biaya Dana } \\
\text { (Rp) }\end{array}$ \\
\hline 2018 & 5.082 .347 .000 & 4 & 203.293 .880 \\
\hline
\end{tabular}

Sumber : PT. BPR. Balaguna Perasta Klungkung

Dari tabel 4.4 diatas dapat dicari biaya dana rata-rata tertimbang untuk tabungan sebagai berikut :

Cost of fund $=203.293 .880 / 5.082 .347 .000 \times 100 \%=4,00 \%$.

Dan untuk biaya dana rata-rata tertimbang Deposito dapat dilihat pada tabel 4.5

Tabel 4.5

Biaya Dana Deposito

PT. BPR. Balaguna Perasta Klungkung

Tahun 2016

\begin{tabular}{|c|c|c|c|}
\hline Jumlah Dana (Rp) & $\begin{array}{c}\text { Jangka } \\
\text { Waktu } \\
\text { (Bulan) }\end{array}$ & $\begin{array}{c}\text { Tingkat Bunga } \\
\mathbf{( \% )}\end{array}$ & Biaya Dana (Rp) \\
\hline 2.792 .400 .000 & 1 & 5 & 139.620 .000 \\
\hline 4.112 .000 .000 & 3 & 6 & 246.720 .000 \\
\hline 4.642 .050 .000 & 6 & 8 & 348.153 .750 \\
\hline 1.106 .050 .000 & 12 & 10 & $\mathbf{8 4 5 . 0 9 8 . 7 5 0}$ \\
\hline $\mathbf{1 2 . 6 5 2 . 5 0 0 . 0 0 0}$ & & & \\
\hline
\end{tabular}

Sumber : PT. BPR. Balaguna Perasta Klungkung

Dari tabel 4.5 diatas dapat dicari biaya dana rata-rata tertimbang untuk deposito berjangka sebagai berikut :

Cost of Fund $=845.098 .750 / 12.652 .500 .000 \times 100 \%=6,679 \%$ dibulatkan $(6,70 \%)$ 
Dengan melihat tabel 5 dan tabel 6 diatas hasil dari biaya dana untuk tabungan sebesar 4\% dan biaya dana untuk deposito berjangka sebesar 6,7\% maka dapat dihitung besarnya total cost of fund dari keseluruhan sumber dana tersebut. Perhitungan total cost of fund sumber dana secara keseluruhan tersebut dapat dilihat pada tabel 4.6.

\section{Tabel 4.6}

Sumber Dana Tabungan dan Deposito Berjangka

PT. BPR. Balaguna Perasta Klungkung Tahun 2018

\begin{tabular}{|l|r|c|r|}
\hline \multicolumn{1}{|c|}{ Sumber Dana } & Jumlah Dana (Rp) & $\begin{array}{c}\text { Tingkat Bunga } \\
(\mathbf{\%})\end{array}$ & Biaya Dana \\
\hline Deposito berjangka & 12.652 .500 .000 & 6,7 & 847.717 .500 \\
\hline Tabungan & 5.082 .347 .000 & 4 & 203.293 .880 \\
\hline & $\mathbf{1 7 . 7 3 4 . 8 4 7 . 0 0 0}$ & & $\mathbf{1 . 0 5 1 . 0 1 1 . 3 8 0}$ \\
& & & \\
\hline
\end{tabular}

Sumber : PT. BPR. Balaguna Perasta Klungkung

Dari tabel 4.6 diatas dapat dicari total cost of fund untuk biaya dana deposito berjangka dan biaya dana tabungan sebagai berikut :

Total Cost of Fund $=1.051 .011 .380 / 17.734 .847 .000 \times 100 \%=5,926 \%$ dibulatkan $(5.90$ $\%)$.

\section{Perhitungan Cost of Loanable Funds}

Menentukan berapa besarnya tingkat bunga kredit yang dikenakan kepada nasabah/ debitur (loan pricing sangat dipengaruhi oleh berbagai variabel yaitu cost of loanable fund, spread, biaya over head, pajak dan premi resiko yang diperkirakan semuanya dinyatakan dalam persentase tertentu.

\section{a. Perhitungan Cost of Loanable Fund}

Selanjutnya untuk menghitung total cost of loanable fund, diasumsikan ketentuan Reserve Requirement (RR) untuk masing-masing sumber dana sebesar 5\%. Perhitungan cost of Loanable dari keseluruhan sumber dana tersebut setelah memperhitungkan ketentuan RR dapat dilihat pada tabel 4.7. 
Tabel 4.7

Sumber Dana Tabungan dan Deposito

Di PT. BPR. Balaguna Perasta Klungkung

\begin{tabular}{|l|c|c|c|c|c|}
\hline & Jumlah & RR & $\begin{array}{c}\text { Loanable Fund } \\
\text { (Rp) }\end{array}$ & $\begin{array}{c}\text { Tingkat } \\
\text { Bunga } \\
\mathbf{( \% )}\end{array}$ & $\begin{array}{c}\text { Biaya Dana } \\
\text { (Rp) }\end{array}$ \\
\hline $\begin{array}{l}\text { Deposito } \\
\text { berjangka }\end{array}$ & 12.652 .500 .000 & 5,0 & 12.019 .875 .000 & 6,7 & 847.717 .500 \\
\hline Tabungan & 5.082 .347 .000 & 5,0 & 4.828 .229 .650 & 4 & 203.293 .880 \\
\hline Jumlah & $\mathbf{1 7 . 7 3 4 . 8 4 7 . 0 0 0}$ & & $\mathbf{1 6 . 8 4 8 . 1 0 4 . 6 5 0}$ & & $\mathbf{1 . 0 5 1 . 0 1 1 . 3 8}$ \\
& & & & & $\mathbf{0}$ \\
\hline
\end{tabular}

Sumber : PT. BPR. Balaguna Perasta Klungkung

Dengan melihat tabel 4.7 dapat dicari perhitungan Total Cost of Loanable Fund dari keseluruhan sumber dana sebagai berikut : Total Cost of Loanable Fund =: 1.051.011.380/16.848.104.650 x $100 \%=6,238 \%$ pembulatan $6,2 \%$. Dari hasi perhitungan Total Cost of Loanable Fund tersebut diatas, maka Cost of Loanable Fund dapat dihitung pula $100: 95 \times 5,90 \%=6,20 \%$. Jadi total cost of loanable fund harus selalu lebih tinggi dari cost of fund dimana Total Cost of Loanable Fund yang di dapat sebesar $6,20 \%$, sedangkan total cost of fund sebesar 5,90\%. Reserve requirement sebesar 5\% berarti dana yang dapat digunakan atau dipinjamkan sebenarnya adalah $100 \%-5 \%=95 \%$

b. Spread

Spread selalu dinyatakan dalam persentase, misalnya dalam menghitung tingkat bunga kredit (Base Landing Rate) bank menentukan spread sebesar 3,0\% yang dihitung dari perkiraan keuntungan yang di inginkan oleh bank.

c. Biaya Overhead.

Biaya overhead yang dikeluarkan bank sebesar Rp. 1.284.906.000, sementara jumlah dana yang berhasil dikumpulkan Rp. 17.734.847.000, maka biaya over head bank adalah : Biaya overhead $=1.284 .906 .000: 17.734 .847 .000 \times 100 \%=7,25 \%$ Jadi biaya overhead untuk PT. BPR. Balaguna Perasta Klungkung adalah 7,25\%. 
d. Premi Resiko

Premi resiko dapat diketahui dari pengalaman bank dalam pengelolaan kredit, yaitu dengan dilakukan penilaian atas kualitas kredit bermasalah. Semakin tinggi resiko yang di hadapi bank. Apabila diasumsikan outstanding loan atau saldo debet bank rata-rata sebesar Rp. 16.216.758.175 dan kolektibilitas kredit masing-masing, lancar $85 \%$, kurang lancar $6 \%$, diragukan $5 \%$, macet $4 \%$, maka jumlah kredit berdasarkan tingkat kolektibilitasnya dan jumlah cadangan penghapusan kredit dapat dihitung sebagaimana yang dilihat pada tabel 4.8.

Tabel 4.8

Jumlah Cadangan Penghapusan Kredit

Di PT. BPR. Balaguna Perasta Klungkung

Outstanding Loan = Rp. 16.216.758.175

\begin{tabular}{|l|c|c|c|c|}
\hline \multicolumn{1}{|c|}{ Kolektibilitas } & $\begin{array}{c}\text { Kolektibilitas } \\
\text { Kredit }\end{array}$ & $\begin{array}{c}\text { Kredit yang di } \\
\text { Klasifikasikan } \\
\text { (Rp) }\end{array}$ & $\begin{array}{c}\text { Cad. Pengha } \\
\text { pusan }\end{array}$ & \multicolumn{1}{c|}{$\begin{array}{c}\text { Jumlah cadangan } \\
\text { penghapusan } \\
\text { (Rp) }\end{array}$} \\
\hline $\begin{array}{l}\text { Cadangan } \\
\text { Umum }\end{array}$ & - & - & $1,0 \%$ & 162.167 .582 \\
$\begin{array}{l}\text { Cadangan } \\
\text { Khusus }\end{array}$ & & & & \\
1. Lancar & & & & \\
2.Kurang lancar & $85 \%$ & 15.026 .269 .475 & - & \\
3. Diragukan & $6 \%$ & 588.830 .850 & $10 \%$ & 58.883 .085 \\
4. Macet & $5 \%$ & 567.644 .650 & $50 \%$ & 283.822 .325 \\
& $4 \%$ & 34.013 .200 & $100 \%$ & 34.013 .200 \\
\hline & $\mathbf{1 0 0 \%}$ & $\mathbf{1 6 . 2 1 6 . 7 5 8 . 1 7 5}$ & & $\mathbf{5 3 8 . 8 8 6 . 1 9 2}$ \\
\hline
\end{tabular}

Sumber : PT. BPR. Balaguna Perasta Klungkung

Dengan melihat tabel 4.8 diatas maka premi resiko kredit dapat dihitung sebagai berikut :

Premi Resiko $=538.886 .192: 16.216 .758 .175 \times 100 \%=3,32 \%$

e. Base Landing Rate

Selanjutnya dengan menggunakan angka-angka perhitungan tersebut diatas dapat ditentukan besarnya base landing rate bank sebagai berikut : 
1. Cost of Loanable Fund $=6,20 \%$

2. Overhead

Cost of Money

$\begin{array}{lrr}= & 7,25 & \% \\ = & 13,45 & \%\end{array}$

3. Spread

$\mathrm{COM}+$ Spread

$\begin{array}{rrr}= & 3,00 & \% \\ = & 16,45 & \%\end{array}$

4. Pajak $1 \%$

$=1,00 \quad \%$

5. Premi Resiko

6. Base Landing Rate

$\begin{array}{lll}= & 3,32 & \% \\ = & 20,77 & \%\end{array}$

Dari hasil perhitungan base landing rate tersebut di atas di dapat base landing rate sebesar 20,77 \%. Apabila base landing rate pada market sebesar 21,6 $\%$ sedangkan base landing rate untuk PT. BPR. Balaguna Perasta Klungkung sebesar 20,77 \% maka dengan adanya kebijakan atas komponen biaya yang mempengaruhi tingkat bunga maka base landing rate bank tersebut menjadi sangat kompetitif.

b. Strategi Penetapan Suku Bunga untuk meningkatkan penjualan kredit di Bank Perkreditan Rakyat (BPR) Balaguna Perasta di Kabupaten Klungkung.

Untuk menilai resiko kredit bagi seorang pelanggan/nasabah, maka pihak bank dapat melakukan penilaian dengan $5 \mathrm{C}$ dari calon pelanggannya/nasabahnya, yaitu dengan memperhatikan : Karakter, Kemampuan, Modal, Jaminan, dan Kondisi perekonomian. Berdasarkan hasil wawancara kepada Direktur AA. Istri Kartika, SE. MM. mengatakan : Dalam meningkatkan pemberian kredit, pihak Bank Perkreditan Rakyat (BPR) Balaguna Perasta di Kabupaten Klungkung sudah melakukan berbagai strategi dalam meningkatkan penjualan kredit yaitu menurunkan tingkat suku bunga kredit, penurunan biaya administrasi dan meningkatkan pelayanan kepada nasabah. Hal ini tentu tetap berpatokan pada prinsip kehati-hatian dengan memperhatikan 5C. (Hasil wawancara pada tanggal 25 Juni 2019).

Dari hasil wawancacara tersebut penulis melihat bahwa setiap pemohon kredit baik yang baru mengusulkan maupun yang sudah melakukan pinjaman, selalu diwajibkan memenuhi aturan persyaratan-persyaratan yang dibutuhkan. Kemudian dilakukan wawancara kepada kepala bagian perkreditan bernama I Wayan Sadia Wirawan,SE. mengatakan untuk memberikan kredit selalu juga berhati-hati agar tidak terjadi kredit bermasalah dikemudian hari mengatakan bahwa : Dalam melakukan seleksi pemberian kredit pihaknya selalu berhati-hati dan senantiasa berpatokan pada peraturan Otoritas Jasa Keuangan dan memperhatikan prinsip-prinsip 5 C seperti : Karakter, Kemampuan, Modal, 
Jaminan, dan Kondisi perekonomian, sehingga harapannya kemudian hari tidak menimbulkan masalah perkreditan. (Hasil wawancara pada tanggal 26 Juni 2019).

Dari hasil pemantauan di lapangan disamping penilaian menggunakan prinsip lima $\mathrm{C}$, juga di lakukan pemilihan/seleksi pelanggan/nasabah menggunakan analisis keuangan. Dalam analisis ini pertama-tama ditentukan faktor-faktor penting yang dapat membedakan baik buruknya seorang pelanggan. Faktor-faktor tersebut dapat berupa : current ratio, quick ratio, debt to assets, inventory turnover, profit margin, dan rasio lainnya.

Lebih lanjut ditemui salah satu nasabah atas nama I Wayan Narka mengatakan bahwa yang bersangkutan pernah melakukan peminjaman kredit di Bank Perkreditan Rakyat (BPR) Balaguna Perasta di Kabupaten Klungkung sebagai berikut : Saya sebagai nasabah sudah lama, dan sudah berulang-ulang melakukan pinjaman kredit atas usaha perternakan yang saya lakoni selama ini. Dan masalah bunga keditnya tidak begitu rendah dan tidak begitu tinggi (Sedang-sedang aja), sehingga saya tetap menggunakan Bank Perkreditan Rakyat (BPR) Balaguna Perasta di Kabupaten Klungkung selama ini (Hasil wawancara pada tanggal 27 Juni 2019). Selanjutnya ditemui nasabah baru atas nama Ni Nengah Partini akan melakukan peminjaman dana/kredit dalam usahanya di bidang perdagangan mengatakan bahwa : Saja mengenal Bank Perkreditan Rakyat (BPR) Balaguna Perasta di Kabupaten Klungkung dari beberapa bank yang ada biasa-biasa saja, yang penting dalam proses pemberian kredit lancar (tidak berbelit-belit) dan masalah tingkat suku bunga kreditnya juga tidak mahal (Masih ada lebih rendah mapun lebih tinggi) sehingga saya memutuskan meminjam di bank ini. (Wawancara pada tanggal 27 Juni 2019).

Berdasarkan uraian di atas sudah jelas bank sangat berhati-hati dan salulu berpikan dengan aturan perbankan untuk memberikan pelayanan perkreditan disamping juga menggunakan beberapa indicator adalah sebagai berikut : Batas kredit yang diberikan, Syarat-syarat Kredit dan Kebijaksanaan Penagihan.

Jadi dari Strategi Penetapan Suku Bunga untuk meningkatkan penjualan kredit di Bank Perkreditan Rakyat (BPR) Balaguna Perasta di Kabupaten Klungkung tidak efektif karena dari pengakuannya nasasumber mengabaikan tingkat suku bunga, justru berpatokan pada pelayanan dan prosedur serta aturan yang berlaku. 


\section{PEMBAHASAN}

Berdasarkan hasil dan analisis masalah pada bab sebelumnya maka pembahasan dalam penelitian ini adalah :

1. Analisis Penetapan suku bunga kredit di Bank Perkreditan Rakyat (BPR) Balaguna Perasta di Kabupaten Klungkung.

Dalam pengelolaan dana bank yaitu bersumber dari pihak ketiga yaitu berupa simpanan dalam bentuk tabungan Dalam menghimpun dana dalam bentuk tabungan bank memberikan fasilitas lebih kepada nasabahnya dengan menggunakan sistem kolektor yang mana tabungan dikolek setiap harinya tanpa nasabah harus datang kekantor. Tingkat suku tabungan yang diberikan sebesar 4\% p.a yang dihitung dari saldo minimum nasabah. Adapun jumlah tabungan dapat pada tahun 2018 adalah sebesar Rp 5.082.347.000. maupun deposito bahwa semakin panjang jangka waktu deposito maka semakin besar bunga yang diberikan oleh PT. BPR Balaguna Perasta, dengan suku bunga tertinggi sebesar $10 \%$ p.a (sesuai suku bunga LPS). Dari sumber dana ini bank harus menanggung biaya bunga atau premi resiko selain biaya operasional lainnya seperti overhead, spread, pajak dan premi resiko. Dari hasil perhitungan biaya dana bank (Base Landing Rate) pada PT. BPR Balaguna Perasta Klungkung diperoleh dari cost of loanable funds $=6,20 \%$, Overhead $=7,25 \%$, Spread $=3,00 \%$, Pajak 1\% $=1,00 \%$, Premi Resiko $=3,32 \%$, maka Base Landing Rate diperoleh $=20,77 \%$. Dan hasil perhitungan rata-rata tingkat suku bunga kredit BPR di Kabupaten Klungkung diperoleh sebesar 21.6\% p.a, Sedamgkan PT. BPR. Balaguna Perasta dalam penyaluran krditnya memberikan suku bunga kredit rata-rata sebesar 19,1 \% p.a (sesuai laporan keuangan 2018), dan berdasarkan hasil perhitungan base landing rate tersebut di atas di diperoleh sebesar 20,77\%, sehingga dengan demikian penetapan suku bunga sebesar 19,1 \% p.a yang dilakukan oleh Bank Perkreditan Rakyat (BPR) Balaguna Perasta di Kabupaten Klungkung belum idial karena Base Landing Rate diperoleh $=20,77 \%$ sedangkan bank penyaluran krditnya dengan suku bunga kredit ratarata sebesar 19,1\% p.a (sesuai laporan keuangan 2018) yang menyebabkan kehilangan pendapatan sebesar $1,67 \%$.

2. Analsisis Strategi Penetapan Suku Bunga untuk meningkatkan penjualan kredit di Bank Perkreditan Rakyat (BPR) Balaguna Perasta di Kabupaten Klungkung.

Dari prosedur pemberian kredit pada umumnya sudah baik. Karena prosedur pemberian kredit telah menerapkan sistem kehati-hatian dalam pemberian kredit. Terutama mereka telah menerapkan prinsip 5'C pada analisa kredit yang mencakup analisa character, 
capacity, capital, collateral, condition of economic. Selain itu alur prosedur pemberian kredit telah mencerminkan pemberian kredit yang sesuai dengan ketentuan kebijakan penyaluran kredit yang bertolok ukur pada keputusan Bank Indonesia. Penerapan kebijakan kredit bank juga baik. Adapun kebijakan dalam penyaluran kredit yakni syarat pengajuan kredit, batas kewenangan pemberian kredit, suku bunga kredit, sanksi yang diberikan semuanya sesuai dengan peraturan yang ditetapkan.

Sedangkan penunggakan kredit yang terjadi disebabkan oleh kegagalan usaha debitur, adanya itikad tidak baik dari debitur, pengawasan eksternal yang belum maksimal dari pihak bank dan faktor lain diluar kreditur dan debitur. Maka diperlukan tindakan untuk menekan terjadinya penunggakan kredit antara lain pelaksanaan inspeksi on the spot dan pembinaan debitur. Bank harus mempunyai prosedur dalam penagihan piutang yang telah jatuh tempo. Banyak prosedur penagihan yang dapat dipergunakan.

Jadi dengan demikian Strategi Penetapan Suku Bunga untuk meningkatkan penjualan kredit di Bank Perkreditan Rakyat (BPR) Balaguna Perasta di Kabupaten Klungkung tidak efektif.

\section{PENUTUP}

Berdasarkan hasil perhitungan rata-rata tingkat suku bunga kredit BPR di Kabupaten Klungkung sebesar $21.6 \%$ p.a, Sedamgkan penyaluran krditnya memberikan suku bunga kredit rata-rata sebesar 19,1 \% p.a (sesuai laporan keuangan 2018), dan berdasarkan hasil perhitungan base landing rate tersebut di atas di diperoleh sebesar 20,77\%, sehingga dengan demikian penetapan suku bunga yang dilakukan oleh Bank Perkreditan Rakyat (BPR) Balaguna Perasta di Kabupaten Klungkung belum ideal. Dalam memberi dan pinjaman kredit bank selalu berpatokan kepada aturan/prosedur pemberian kredit dengan menerapkan prinsip kehati-hatian. Terutama telah menerapkan prinsip 5'C yang mencakup analisa character, capacity, capital, collateral, condition of economic disamping prosedur pemberian kredit sesuai dengan ketentuan Bank Indonesia yakni syarat pengajuan kredit, batas kewenangan pemberian kredit, suku bunga kredit, sanksi yang diberikan semuanya sesuai dengan peraturan yang ditetapkan. Sehingga dengan demimkian Strategi Penetapan Suku Bunga untuk meningkatkan penjualan kredit di Bank Perkreditan Rakyat (BPR) Balaguna Perasta di Kabupaten Klungkung tidak banyak mempengaruhi dalam pemberian kedit/tidak efektif 


\section{DAFTAR PUSTAKA}

Adnyasuari, P.A.S., and Darma, G.S. (2017). Technology Acceptance Model dan ESatisfaction in Mobile Banking, Jurnal Manajemen \& Bisnis, 14 (2): 1-12.

Arsriani, I.A.I., and Darma, G.S. (2013). Peran Media Sosial Online Dan Komunitas Terhadap Keputusan Nasabah Bank, Jurnal Manajemen dan Bisnis, 10 (2): 48-68.

Arianti, N.L.N., Darma, G.S., Maradona, A.F., and Mahyuni, L.P. (2019). Menakar Keraguan Penggunaan QR Code Dalam Transaksi Bisnis, Jurnal Manajemen \& Bisnis, 16 (2): 67 78.

Budiasni, N.W.N., and Darma, G.S. (2016). Penerapan Corporate Social Responsibility pada Lembaga Keuangan Berbasis Kearifan Lokal, Jurnal Manajemen \& Bisnis, 13 (2): 119.

Dewi, N.M.A.T., and Darma, G.S. (2016). Efektivitas Leadership, Growth Performance dan Regulasi Otoritas Jasa Keuangan, Jurnal Manajemen \& Bisnis, 13 (1): 1-13.

Dewi, M.V.K., and Darma, G.S. (2019). The Role of Marketing \& Competitive Intelligence In Industrial Revolution 4.0, Jurnal Manajemen \& Bisnis, 16 (1): 1-12.

Hartanto. (2003). Akuntansi Untuk Usahawan, Jakarta: Universitas Indonesia.

Kasmir. (2004). Manajemen Perbankan. Edisi Ketiga. Jakarta: PT. Raja Grafindo.

Lexy, M.J. (2010). Metodologi Penelitian Kualitatif. Bandung: PT. Remaja Rosdakarya.

Mulyadi. (2001). Pemeriksaan Akuntan. Yogyakarta: Sekolah Tinggi Ilmu Ekonomi EKPN.

Pahlawan, H. (2016). Analisis Pengaruh Biaya Dana (cost of fund) Giro, Tabungan, dan Deposito terhadap Rentabilitas Bank Persero BUMN Indonesia.

Patni, S.S., and Darma, G.S. (2017). Non-Performing Loan, Loan to Deposit Ratio, Net Interest Margin, BOPO, Capital Adequacy Ratio, Return on Asset dan Return on Equity, Jurnal Manajemen \& Bisnis, 14 (2): 166-184.

Permanasari, I.A.S., and Darma, G.S. (2013). Pengaruh Penggunaan Internet Banking Terhadap Rasa Aman, Rasa Percaya Dan Loyalitas Nasabah Dalam Meningkatkan Saldo Bank, Jurnal Manajemen dan Bisnis, 10 (1): 186-204.

Premawati, I.G.A.S., and Darma, G.S. (2017). Pengaruh Ukuran Perusahaan, Pertumbuhan Penjualan, Struktur Aktiva, dan Profitabilitas Terhadap Struktur Modal (Penelitian Di Bursa Efek Indonesia Periode 2011-2015), Jurnal Ilmiah Akuntansi \& Bisnis, 2 (2): 272-286. 
Rusmahadewi, I.A., and Darma, G.S. (2018). Team Engagement and Performance Management (A Study of Banking Industry), Jurnal Manajemen \& Bisnis, 15 (3): 3850 .

Sawitri, P., dan Wicaksono, A. (2007). Faktor - Faktor Base Lending Rate Pt Bank Rakyat Indonesia (Persero) Tbk Tahun 2002 - 2006.

Samadiartha, I.N.D., and Darma, G.S. (2017). Dampak Sistem E-Filing, Pengetahuan Perpajakan, Sosialisasi Perpajakan, Kesadaran Wajib Pajak terhadap Kepatuhan Wajib Pajak, Jurnal Manajemen \& Bisnis, 14 (1): 75-103.

Syamsudin, L. (2001). Manajemen Keuangan Perusahaan (Konsep Aplikasi Dalam Perencanaan Pengawasan dan Pengambilan Keputusan). Rajawali Pers.

Siamat, D. (2005). Manajemen Lembaga Keuangan, Kebijakan Moneter dan Perbankan. Jakarta: FEUI.

Supit, H.A.M., and Darma, G.S. (2018). Aplikasi Mobile Trading Monex Guna Mendukung Customer Relationship Management, Jurnal Manajemen \& Bisnis, 15 (1): 46-60.

Supit, H.A.M., and Darma, G.S. (2018). Enhancing User Experience in Forex Mobile Trading Application to Support Customer Relationship Management, Jurnal Manajemen \& Bisnis, 15 (3): 51-63.

Sudirman, I.W. (1999). Manajemen Perbankan, Edisi Pertama, Cetakan Pertama. PT. BP Denpasar.

Undang-Undang Perbankan No. 10 Tahun 1998. SE BI No. 30/III/UPPP tanggal 30 April 1977, Tentang Penilaian Tingkat Kesehatan Bank.

Widiatmika, P.H., and Darma, G.S. (2018). Good Corporate Governance, Job Motivation, Organization Culture Which Impact Company Financial Performance, Jurnal Manajemen \& Bisnis, 15 (3): 82-99.

Widia, W. (2011). Pengaruh Dana Pihak Ketiga Terhadap Pembiayaan dan Implikasinya Terhadap Laba Bank Syariah (Penelitian Pada Perbankan Syariah di Indonesia. 